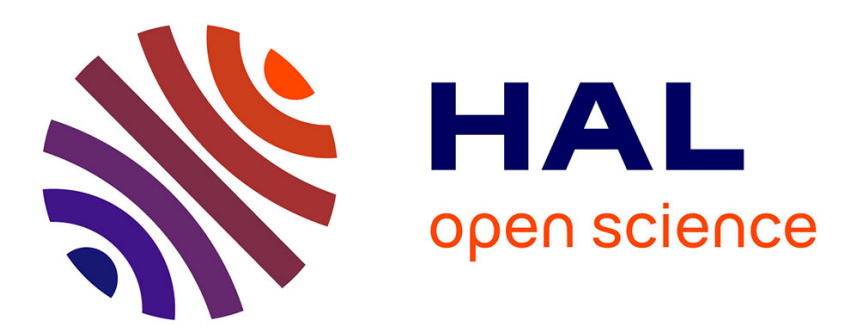

\title{
In situ generation of indium catalysts to grow crystalline silicon nanowires at low temperature on ITO
}

Pierre-Jean Alet, Linwei Yu, Gilles Patriarche, Serge Palacin, Pere Roca I Cabarrocas

\section{- To cite this version:}

Pierre-Jean Alet, Linwei Yu, Gilles Patriarche, Serge Palacin, Pere Roca I Cabarrocas. In situ generation of indium catalysts to grow crystalline silicon nanowires at low temperature on ITO. Journal of Materials Chemistry, 2008, 18, pp.5187-5189. 10.1039/b813046a . cea-01056562

\section{HAL Id: cea-01056562 https://hal-cea.archives-ouvertes.fr/cea-01056562}

Submitted on 20 Aug 2014

HAL is a multi-disciplinary open access archive for the deposit and dissemination of scientific research documents, whether they are published or not. The documents may come from teaching and research institutions in France or abroad, or from public or private research centers.
L'archive ouverte pluridisciplinaire HAL, est destinée au dépôt et à la diffusion de documents scientifiques de niveau recherche, publiés ou non, émanant des établissements d'enseignement et de recherche français ou étrangers, des laboratoires publics ou privés. 


\title{
In situ generation of indium catalysts to grow crystalline silicon nanowires at low temperature on ITO $\dagger$
}

\author{
Pierre-Jean Alet, ${ }^{a b}$ Linwei Yu, ${ }^{b}$ Gilles Patriarche, ${ }^{c}$ Serge Palacin ${ }^{a}$ and Pere Roca i Cabarrocas ${ }^{* b}$
}

\author{
Received 29th July 2008, Accepted 23rd September 2008 \\ First published as an Advance Article on the web 7th October 2008 \\ DOI: $10.1039 / b 813046 a$
}

\begin{abstract}
In situ generation of indium catalyst droplets and subsequent growth of crystalline silicon nanowires on ITO by plasma-enhanced CVD are reported, and the wurtzite ( $\mathrm{Si}-\mathrm{IV})$ phase is clearly evidenced in some wires.
\end{abstract}

Potential applications and fundamental physical studies have driven increasing efforts in the synthesis of semiconductor nanowires, ${ }^{1-3}$ especially silicon nanowires ( $\mathrm{SiNW}$ ). The most common growth mechanism is known as "vapor-liquid-solid" (VLS). ${ }^{4}$ It is based on the dissociation of a precursor gas $\left(\right.$ e.g., $\left.\mathrm{SiH}_{4}\right)$ at the surface of metallic catalyst droplets, the diffusion of constituent atoms (e.g., $\mathrm{Si}$ ) in the droplets, and their precipitation at an interface. Fast diffusion is required to obtain high aspect ratios and high growth rates. Therefore the catalyst droplets should be liquid. This sets the growth temperature above the eutectic point, if any, of the metal/silicon alloy. The most common catalyst, gold, has a eutectic point with silicon at $363{ }^{\circ} \mathrm{C},{ }^{5}$ and the typical growth temperature with this metal is above $450{ }^{\circ} \mathrm{C}$. Indium, the melting point of which is $156.6^{\circ} \mathrm{C}$, can noticeably lower the growth temperature but it oxidizes rapidly and requires surface cleaning before SiNW are grown. ${ }^{6}$

The VLS mechanism can be implemented by laser ablation ${ }^{7}$ or chemical vapor deposition ${ }^{8}$ (CVD). Few attempts to use plasmaenhanced CVD (PECVD) have been reported, even though PECVD helps to broaden the range of metal catalysts and lower the substrate temperature as compared to CVD. ${ }^{6,9-12}$

Many applications foreseen for $\mathrm{SiNW}$ are opto-electronic devices. These would hence greatly benefit from SiNW being directly grown on transparent conductive substrates, such as $\mathrm{In}_{2} \mathrm{O}_{3}: \mathrm{Sn}$ (ITO) or $\mathrm{SnO}_{2}$. Yet few attempts have been reported. ${ }^{13}$ One possible reason is the lack of stability of these substrates at high temperature. In particular, ITO is known to be superficially reduced upon exposure to $\mathrm{SiH}_{4}$ or $\mathrm{H}_{2}$ plasmas above $200{ }^{\circ} \mathrm{C} .{ }^{14}$

In this communication, we propose to turn this sensitivity into an advantage to produce indium catalyst droplets in situ, and to grow SiNW by PECVD directly on ITO.

${ }^{a}$ CEA, IRAMIS, SPCSI, Laboratory of Chemistry at Surfaces and Interfaces, F-91191 Gif-sur-Yvette cedex, France.E-mail: serge.palacin@, cea.fr; Fax: +331690864 62; Tel: +33169081280

${ }^{b}$ LPICM, CNRS/École polytechnique, Route de Saclay, F-91128 Palaiseau cedex, France.E-mail: pere.roca@polytechnique.edu; Fax: +331693343 33; Tel: +33169334314

${ }^{c}$ Laboratoire de Photonique et de Nanostructures, CNRS (UPR 20), Route de Nosay, F-91460 Marcoussis, France. E-mail: Gilles.Patriarche@lpn. cnrs.fr; Fax: +331696360 06; Tel: +33169636173

$\dagger$ Electronic supplementary information (ESI) available: Transmission spectra of the ITO-coated glass samples after $\mathrm{H}_{2}$ treatment. See DOI: $10.1039 / \mathrm{b} 813046 \mathrm{a}$
The main steps of the process are schematically presented in Fig. 1. It is entirely run under vacuum in one single capacitively coupled, radio-frequency (RF) PECVD reactor. The base pressure for our experiments was $5 \times 10^{-6} \mathrm{mbar}$.

In the first step (Fig. 1a), ITO-coated glass $\$$ is exposed to a hydrogen plasma. The substrate temperature is set to a value above the melting point of indium. In our growth experiments, the substrate temperature was $250 \pm 5^{\circ} \mathrm{C}$, at which ITO is known to be superficially reduced on the time-scale of minutes, ${ }^{15}$ and the RF power density was $64 \mathrm{~mW} \mathrm{~cm}{ }^{-2}$. This surface treatment leads to the formation of metallic droplets of indium and tin (Fig. 1b).

Then the hydrogen plasma is stopped and the samples are exposed to low-pressure silane plasma (Fig. 1c). In our experiments, the pressure was $7.4 \times 10^{-2} \mathrm{mbar}$, and the RF power density was $25 \mathrm{~mW} \mathrm{~cm} \mathrm{~cm}^{-2}$. When the substrate is glass or untreated ITO, such a plasma leads to the deposition of hydrogenated amorphous silicon (a-Si:H) through the reaction of $\mathrm{SiH}_{3}$ radicals on the substrate. Here, though, $\mathrm{SiH}_{x}$ species preferentially decompose at the surface of the metallic droplets. Si atoms are dissolved in the indium droplets and then precipitate at the interface with the substrate. This process is faster than the radical-induced growth, so it leads to the growth of structures standing out from the surface. Silicon wires grown through this process have a typical length of $600 \mathrm{~nm}$ after $15 \mathrm{~min}$ of growth.

The catalytic effect of metallic indium is evidenced by deposition on a patterned substrate (Fig. 2). On one part (left of the SEM picture), the ITO coating has been etched off by an acid solution before the plasma treatment, while the other part was protected. The whole sample was then cleaned and exposed to the plasma without any mask.

On the etched part, amorphous silicon, which appears smooth and dark in the SEM image, is deposited. It is characterized by a broad Raman peak near $450 \mathrm{~cm}^{-1}$. In contrast, the ITO-coated part is covered by silicon nanowires, the trunks of which appear bright and the metallic caps appear white. The Raman spectrum of this part shows a sharp peak at $500 \mathrm{~cm}^{-1}$, which indicates that the wires are crystalline. The Raman peaks are moved down by about $20 \mathrm{~cm}^{-1}$ as compared to those of bulk crystalline silicon. This shift may be explained by local heating of the nanowires by the laser beam used in the measurements or by some wires having a Si-IV (wurtzite) crystalline structure. ${ }^{16}$

The catalyst caps, which have been shown by energy dispersive $\mathrm{X}$-ray analysis (EDX) to be indium with an average $1.5 \mathrm{at} \%$ of tin, are generally much larger than the wires which support them (Fig. 3a). Their effective diameter is indeed $220 \mathrm{~nm}$ (standard deviation: $130 \mathrm{~nm}$ ) whereas the average diameter of the wires is 100 $\mathrm{nm}$ (standard deviation: $60 \mathrm{~nm}$ ). This size mismatch is a major 

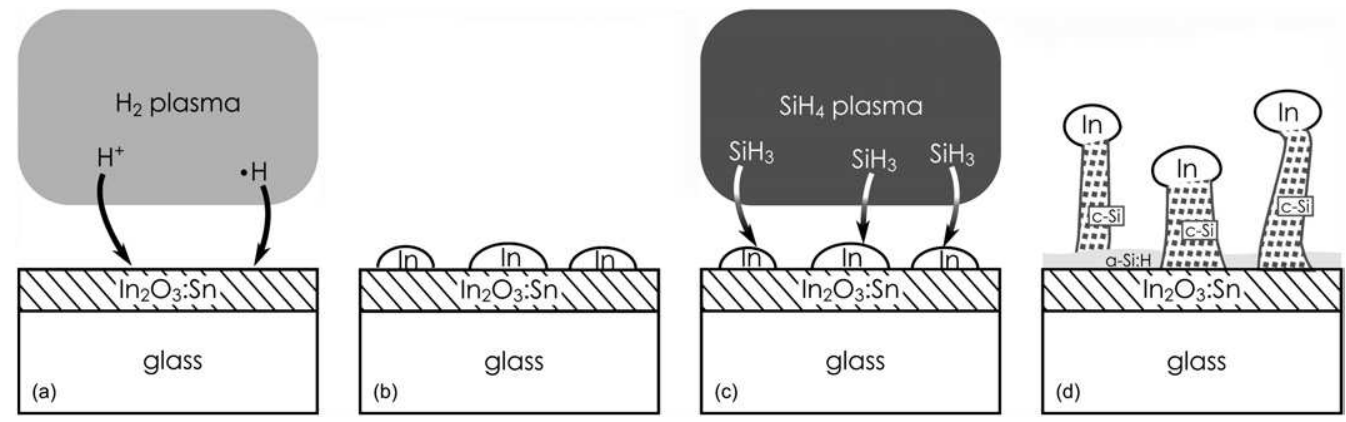

Fig. 1 Schematic steps of the process: (a) superficial reduction by an RF hydrogen plasma; (b) formation of indium droplets; (c) RF silane plasma and preferential dissociation of $\mathrm{SiH}_{x}$ species on indium droplets; (d) formation of indium-capped silicon nanowires.
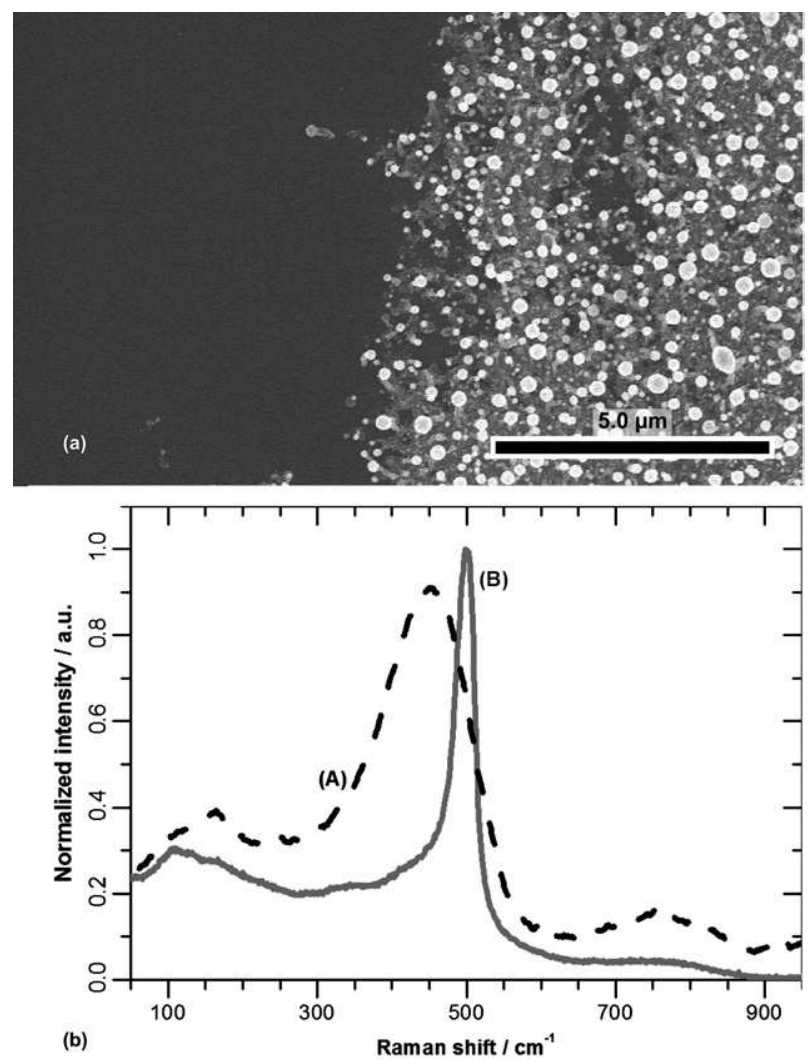

Fig. 2 Localized growth of silicon nanowires on ITO: (a) SEM image of the layer grown on a partially etched ITO coated glass (left: amorphous silicon on etched glass, right: silicon nanowires grown on ITO-coated glass, tilt angle: $30^{\circ}$ ); (b) Raman spectra of the layers deposited (A) on etched glass (dashed black curve) and (B) on ITO-coated glass.

difference with common catalysts. Indeed, gold catalyst droplets always have a diameter which is smaller than or equal to the diameter of the nanowires and in most cases the base of the droplet exactly covers the top of the wire. This difference is explained by the wettability of silicon by gold and indium. The contact angle of $\mathrm{Au}-\mathrm{Si}$ droplets on $\mathrm{Si}(111)$ is $43^{\circ}$ over the temperature range where silicon nanowires are grown, ${ }^{17}$ whereas the contact angle of indium on $\mathrm{Si}(111)$ at $350{ }^{\circ} \mathrm{C}$ is $125^{\circ} .{ }^{18}$ Hence for a given amount of metal, the interface area between silicon and the droplet is much larger with gold than with indium. This way, smaller nanowires can be grown with aggregates of a given size when indium is used instead of gold.

The amount of tin (between 2 at $\%$ and $5 \mathrm{at} \%$ ) and indium $(0.5 \mathrm{at} \%)$ in the wires is much higher than the reported solid solubility in crystalline silicon (36 ppm for indium, ${ }^{19} 0.1 \mathrm{at} \%$ for $\mathrm{tin}^{5}$ ). However, metastable $\mathrm{Si}_{1-x} \mathrm{Sn}_{x}$ alloys with a tin concentration as high as $5.2 \mathrm{at} \%$ have been reported to be grown by molecular beam epitaxy (MBE) with good structural quality. ${ }^{20}$

High resolution transmission electron microscopy confirms that the nanowires are single crystalline. At least two different structures have been identified. The "standard" cubic diamond structure (Si-I) has been observed on wires with diameters larger than $100 \mathrm{~nm}$ (Fig. 3b). The metastable hexagonal wurtzite structure (Si-IV) has been clearly evidenced on nanowires with a diameter of $70 \mathrm{~nm}$. Their cell parameters were determined from the electron diffraction patterns (Fig. 3c). Their values $(a=0.382 \mathrm{~nm}$ and $c=0.634 \mathrm{~nm})$ are in very good agreement with the theoretical ones $(a=0.380 \mathrm{~nm}$ and $c=0.628 \mathrm{~nm})$. The interplanar spacings $(0.317 \mathrm{~nm}, 0.191 \mathrm{~nm}$ and $0.163 \mathrm{~nm}$ ) were attributed to the 0002,2110 and 2112 reflections, respectively. Additional spots, indexed as $1 / 2$ in the $2-1-12$ direction, were observed at $0.326 \mathrm{~nm}$. They reveal a substructure in addition to the hexagonal phase in this direction.

One of the advantages of the method presented here is the ability to grow nanowires on substrates (ITO) which have special optical and electrical properties. It is therefore important to check that those properties are not significantly modified by the $\mathrm{H}_{2}$ treatment. The formation of metallic droplets leads to a reduction in the transmittance of the ITO-coated glass: the transmittance decreased by $3 \%$ after 2 min of high-pressure $\mathrm{H}_{2}$ plasma at $200{ }^{\circ} \mathrm{C}$ and by $13 \%$ after $2 \mathrm{~min}$ at $250^{\circ} \mathrm{C}$. This reduction does not come from changes in the bulk of ITO, but it is due to absorption by metallic tin and diffraction by the droplets (when their typical size is of the same order as the optical wavelength). ${ }^{21}$ These droplets are eventually at the top of the brush of SiNW as catalyst caps, so they do not contribute to light absorption by the substrate after growth. The loss of transmittance reported here should therefore be seen as an upper limit. In addition, the $\mathrm{H}_{2}$ plasma treatment has very little impact on the conductivity of ITO. High-pressure $\mathrm{H}_{2}$ plasma treatment at $200{ }^{\circ} \mathrm{C}(30 \mathrm{~s}$ to $2 \mathrm{~min})$ leads to an increase in the sheet resistance from $10 \Omega \mathrm{sq}^{-1}$ to $14 \Omega \mathrm{sq}^{-1}$; at $250{ }^{\circ} \mathrm{C}$, only a $2 \mathrm{~min}$ treatment leads to a higher value $\left(16 \Omega \mathrm{sq}^{-1}\right)$.

In summary, superficial reduction of a transparent conductive oxide (ITO) by exposure to $\mathrm{H}_{2}$ plasma has been successfully used to create catalyst droplets for the growth of crystalline silicon nanowires. This production of metallic aggregates is carried out in situ, just 

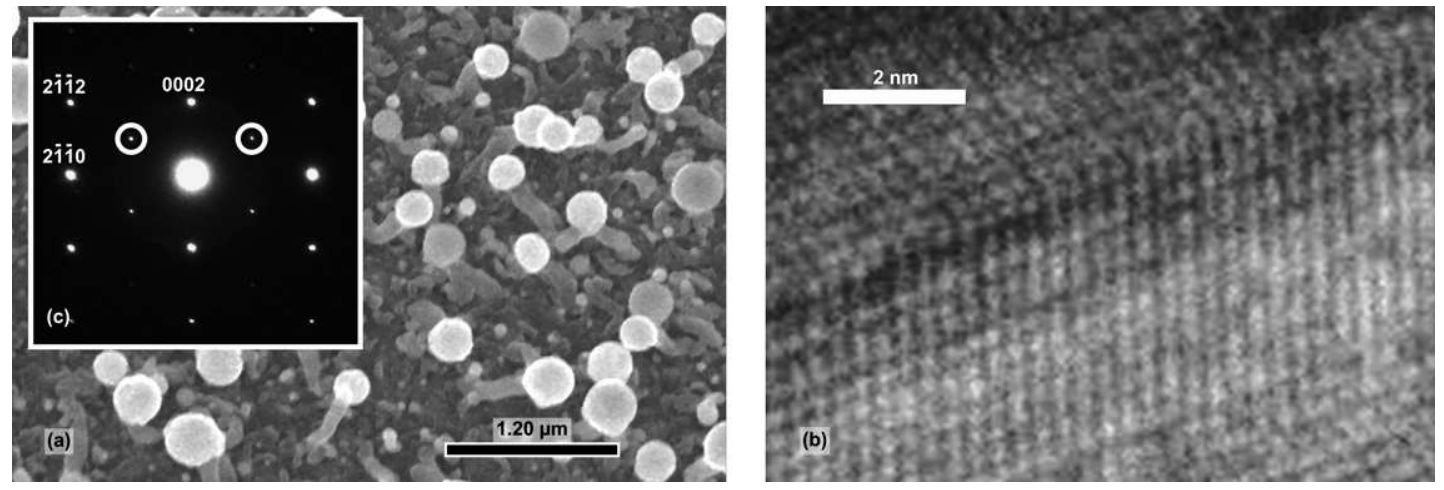

Fig. 3 Microscopic characterization of silicon nanowires grown on ITO: (a) SEM picture (tilt angle: $30^{\circ}$ ); (b) high-resolution TEM image of a nanowire with a cubic structure showing micro twins; (c) selected area electron diffraction pattern of a $<1-100>$ pole axis of a nanowire with wurtzite structure; circled spots evidence a substructure in addition to the hexagonal structure in the 2-1-12 direction.

before the nanowires are actually grown. The low melting point of indium allows the growth to happen at a substrate temperature of $250{ }^{\circ} \mathrm{C}$. Using this method, silicon nanowires can be directly grown on transparent and conductive substrates, whose properties are only marginally damaged upon this treatment. Optimization of the plasma parameters, such as the substrate temperature, power density, length of the treatment, $\mathrm{H}_{2}$ pressure, should allow accurate control of the size and density of the metallic droplets, which in turns control those of the nanowires. Our approach opens the way to many applications and is a step further toward large scale production and effective use of silicon nanowires. In particular, as the brush of nanowires presented here strongly scatters light, it may be of major interest for light trapping in solar cells.

\section{Notes and references}

+ Our substrates were commercial $2.5 \mathrm{~cm} \times 1.7 \mathrm{~cm}$ glass plates coated with about $100 \mathrm{~nm}$ of ITO.

1 H. J. Fan, P. Werner and M. Zacharias, Small, 2006, 2, 700-717.

2 W. Lu and C. M. Lieber, J. Phys. D: Appl. Phys., 2006, 39, R387-R406.

3 Y. Xia, P. Yang, Y. Sun, Y. Wu, B. Mayers, B. Gates, Y. Yin, F. Kim and H. Yan, Adv. Mater., 2003, 15, 353-389.

4 R. S. Wagner and W. C. Ellis, Appl. Phys. Lett., 1964, 4, 89-90.

5 T. B. Massalski, Binary Alloy Phase Diagrams, 2nd edn, ASM International, Materials Park, OH 44073, USA, 1998.
6 F. Iacopi, P. M. Vereecken, M. Schaekers, M. Caymax, N. Moelans, B. Blanpain, O. Richard, C. Detavernier and H. Griffiths, Nanotechnology, 2007, 18, 505307.

7 A. M. Morales and C. M. Lieber, Science, 1998, 279, 208-211.

8 A. I. Hochbaum, R. Fan, R. He and P. Yang, Nano Lett., 2005, 5, 457-460.

9 P. Aella, S. Ingole, W. T. Petuskey and S. T. Picraux, Adv. Mater., 2007, 19, 2603-2607.

10 H. Griffiths, C. Xu, T. Barrass, M. Cooke, F. Iacopi, P. Vereecken and S. Esconjauregui, Surf. Coat. Technol., 2007, 201, 9215-9220.

11 S. Hofmann, C. Ducati, R. J. Neill, S. Piscanec, A. C. Ferrari, J. Geng, R. E. Dunin-Borkowski and J. Robertson, J. Appl. Phys., $2003,94,6005-6012$.

12 M. K. Sunkara, S. Sharma, R. Miranda, G. Lian and E. C. Dickey, Appl. Phys. Lett., 2001, 79, 1546-1548.

13 P.-J. Alet, L. Eude, S. Palacin and P. Roca i Cabarrocas, Phys. Status Solidi A, 2008, 205, 1429-1434.

14 B. Drevillon, S. Kumar, P. Roca i Cabarrocas and J. M. Siefert, Appl. Phys. Lett., 1989, 54, 2088-2090.

15 O. Kuboi, Jpn. J. Appl. Phys., 1981, 20, L783-L786.

16 J. D. Prades, J. Arbiol, A. Cirera, J. R. Morante and A. Fontcuberta i Morral, Appl. Phys. Lett., 2007, 91, 123107.

17 B. Ressel, K. C. Prince, S. Heun and Y. Homma, J. Appl. Phys., 2003, 93, 3886-3892.

18 M. Mattila, T. Hakkarainen, H. Lipsanen, H. Jiang and E. I. Kauppinen, Appl. Phys. Lett., 2006, 89, 063119.

19 S. Solmi, A. Parisini, M. Bersani, D. Giubertoni, V. Soncini, G. Carnevale, A. Benvenuti and A. Marmiroli, J. Appl. Phys., 2002, 92, 1361-1366.

20 S. Y. Shiryaev, J. L. Hansen, P. Kringhoj and A. N. Larsen, Appl. Phys. Lett., 1995, 67, 2287-2289.

21 R. Banerjee, S. Ray, N. Basu, A. K. Batabyal and A. K. Barua, J. Appl. Phys., 1987, 62, 912-916. 